\title{
Darier-Roussy Sarcoidosis Mimicking Metastatic Breast Cancer
}

\author{
Lokesh Viswanath $^{\mathrm{a}} \quad$ Siddanna Pallade $^{\mathrm{a}} \quad$ B. Krishnamurthy ${ }^{\mathrm{b}}$ \\ T. Naveen ${ }^{\mathrm{a}}$ B.L. Preethic ${ }^{\mathrm{c}}$ K.P.R. Pramod ${ }^{\mathrm{a}}$ Obula Reddy $^{\mathrm{d}}$ \\ G. Padma ${ }^{\mathrm{a}}$ \\ Departments of a Radiation Oncology and ${ }^{b}$ Surgical Oncology, Kidwai Memorial \\ Institute of Oncology, 'Department of Physiology, M.S. Ramaiah Medical College, \\ ${ }^{\mathrm{d}}$ Department of Cytology, KMIO, Bangalore, India
}

\section{Key Words}

Sarcoidosis · Breast cancer · Metastasis · Subcutaneous sarcoidosis

\begin{abstract}
Subcutaneous sarcoidosis (also known as 'Darier-Roussy sarcoid') is a cutaneous condition characterized by numerous deep-seated nodules on the trunk and extremities. Coexistence of sarcoidosis and breast cancer are reported in the literature, but there will always be a chance of misdiagnosis. It is very crucial to obtain a tissue diagnosis of suspicious metastatic lesions. We report a case of breast cancer presenting with a subcutaneous sarcoid lesion masquerading as a metastatic lesion. A 50-year-old female patient, who had had cancer of the left breast, was on hormone therapy 2 years after treatment with surgery, radiotherapy and chemotherapy. The patient presented with a sudden onset of a forehead subcutaneous swelling mimicking metastasis which on excision biopsy was proved to be sarcoidosis. In India, sarcoidosis is reported rarely. We have to keep in mind that there is a chance of the metastatic lesions being of sarcoidosis origin or another granulomatous disease. To avoid misdiagnosis, it is better to obtain a tissue diagnosis.
\end{abstract}

\section{Introduction}

Sarcoidosis (flesh-like process) also called sarcoid or Besnier-Boeck disease is a multisystem disorder of unknown etiology which is characterized by non-caseating granulomas (small inflammatory nodules) mainly involving the lungs (90\%), lymph nodes, eyes, and skin. The first reported case bearing the clinicopathological features of subcutaneous sarcoidosis was described by Darier and Roussy in 1904. Subcutaneous sarcoidosis (also known as 'Darier-Roussy sarcoid') is a cutaneous condition 
characterized by numerous 0.3 to $0.5-\mathrm{cm}$ deep-seated nodules on the trunk and extremities [1]. Sarcoidosis most commonly affects young adults of both sexes, although studies have reported more cases in females. Incidence is highest in individuals younger than 40 and peaks in the age group from 20-29 years; a second peak is observed for women over $50[2,3]$. Sarcoidosis is less commonly reported in India [4]. Sarcoidosis and breast carcinoma are two distinct diseases that affect women [5]. Coexistence of sarcoidosis and breast cancer is reported in the literature, but there will always be a chance of misdiagnosis. It is very crucial to obtain a tissue diagnosis of suspicious metastatic lesions. We report a case of breast cancer presenting with a subcutaneous sarcoid lesion masquerading as a metastatic lesion.

\section{Case Report}

A 50-year-old female patient with type 2 diabetes who presented with cancer of the left breast (stage T4a N1 M0) was treated with surgery (left total mastectomy and axillary clearance), followed by radiotherapy to the chest wall (to a dose of 50 Gray in 25 fractions, 5 fractions/week) and 6 cycles of chemotherapy (FAC) followed by tamoxifen $20 \mathrm{mg}$ once daily planned for the next 5 years. Her histopathological details were infiltrating duct carcinoma grade 3,3 out of 5 axillary nodes had metastatic deposits with 1 node having perinodal spread. Hormone receptor status was triple negative, that is $\mathrm{ER} / \mathrm{PR} / \mathrm{Her} / 2$ neu. Metastasis workup was negative.

Two years after surgery, the patient was on hormone therapy (tamoxifen), and during this routine follow-up period, routine ultrasound of the abdomen and pelvis with gynecological checkup revealed an endocervical polyp in the uterine cervix which was treated with local excision and was histologically a leiomyomatous polyp. In the next follow-up month the patient presented with sudden onset (1 week) of a painless swelling in the glabellar region of the forehead. She had a diffuse $4 \times 4 \mathrm{~cm}$, subcutaneous deposit. In view of the sudden onset and the patient being a known case of breast cancer with node positivity and perinodal spread, a clinical diagnosis of subcutaneous metastatic deposit was made. Clinically, the patient was locoregionally controlled for her breast cancer and other investigations for metastasis were made, such as chest X-ray, ultrasonogram of the abdomen and pelvis, and bone scan, which were also normal.

Local excision of the lesion revealed a grayish brown tissue of $2.5 \times 1.5 \mathrm{~cm}$, cut surface was grayish white with nodularity. Microscopically, there were multiple discrete epithelioid cell granuloma with minimal lymphocytic response and small foci of necrosis. In some places, there were giant cells containing refractory crystalline material. Few other giant cells contained asteroid bodies (fig. 1). The patient was treated with chloroquine for the next 6 months CQ, $750 \mathrm{mg} /$ day 11 . Ten years after surgery the patient continues to be disease free.

\section{Discussion}

Sarcoidosis and breast carcinoma are two distinct diseases that affect women. They can present either at the same time or in sequence. Both diseases can present with pulmonary nodules, which mimic metastasis or non-malignant disease in either of the cases leading to misdiagnosis. Subcutaneous lesions in systemic sarcoidosis are well-known, but uncommon. Rarely, subcutaneous sarcoidosis occurs in patients without evidence of systemic disease $[6,7]$.

Although there have been many theories on the link between sarcoidosis and malignancy, the association remains unproven [6]. Most researchers believe that patients with pulmonary sarcoidosis are predisposed to develop malignancies [9], but others presume that malignancies lead to sarcoidosis. Some authors even hypothesize that malignancy gives rise to sarcoidosis. The cause of a high risk of malignant neoplasms in patients with pulmonary sarcoidosis remains obscure. Sarcoidosis patients develop breast 


\begin{tabular}{|c|c|c|c|}
\hline $\begin{array}{c}\text { Case Reports in } \\
\text { Onacily }\end{array}$ & $\begin{array}{l}\text { Case Rep Oncol 2009;2:251-254 } \\
\text { DOI: } 10.1159 / 000262412\end{array}$ & Published online: December 18, 2009 & \begin{tabular}{|l} 
@ 2009 S. Karger AG, Basel \\
ISSN $1662-6575$ \\
www.karger.com/cro
\end{tabular} \\
\hline
\end{tabular}

cancer at an expected frequency, although the literature suggests an increased incidence of testicular cancers and lymphomas in patients with systemic sarcoidosis.

Chen et al. [5] reported 3 cases of breast cancer with coexistent pulmonary nodules which on biopsy revealed pulmonary sarcoidosis. Tolaney et al. [12] also had the same clinical situation with pulmonary nodules in advanced breast cancer which proved to be sarcoid lesions on tissue biopsy. An unfortunate consequence of the presence of both entities in the same patient is the risk of misdiagnosis and incorrect treatment. To avoid such mishaps it is always better to obtain a tissue biopsy of the suspicious metastatic lesions.

There are case reports on subcutaneous sarcoidosis mimicking metastatic breast cancer by Mingins et al. [6], Tolaney et al. [8], and Gallimore et al. [10]. In our case we had high suspicion of a metastatic lesion, but in view of all other metastatic workup being negative, we performed an excision of the forehead lesion. Fortunately, histopathology revealed subcutaneous sarcoidosis and averted further metastatic management. The patient continues to be disease free even after 10 years. This is probably the first case of subcutaneous sarcoidosis without systemic sarcoidosis in a breast cancer patient $[6,8,10$, $11]$.

In conclusion, sarcoidosis is rarely reported in India. We have to keep in mind that there is a chance of the metastatic lesions being of sarcoidosis origin or other granulomatous disease. To avoid misdiagnosis, it is better to obtain a tissue diagnosis.

Fig. 1. Multiple discrete epithelioid cell granuloma with minimal lymphocytic response with few other giant cells containing asteroid bodies.

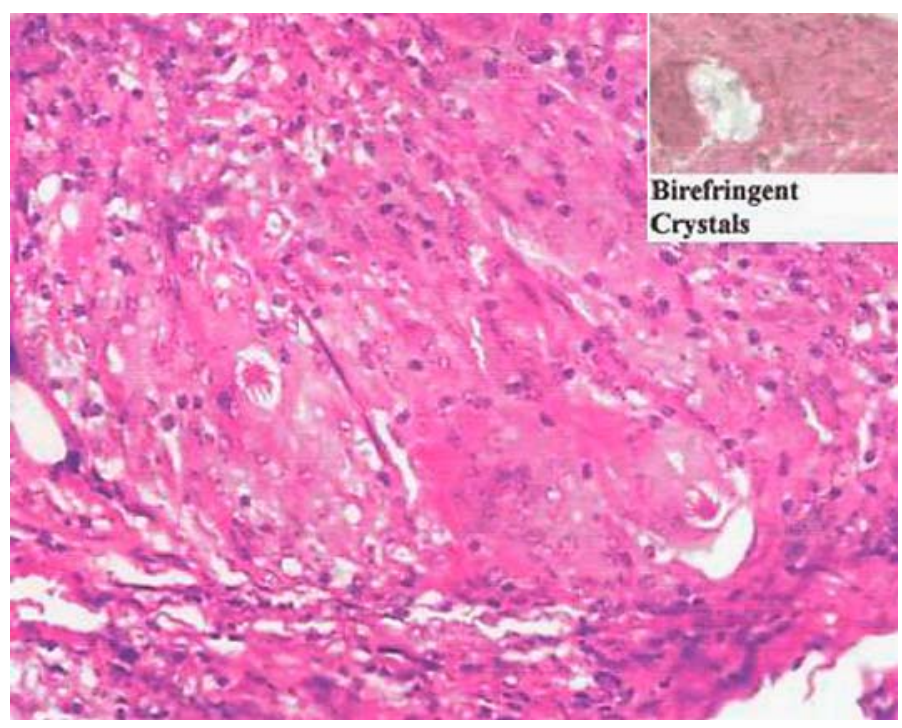




\section{References}

1 James WD, Berger TG: Andrews' Diseases of the Skin: Clinical Dermatology. Saunders Elsevier, 2006.

2 Baughman RP, Lower EE, du Bois RM: Sarcoidosis. Lancet 2003;361:1111-1118.

3 Nunes H, Bouvry D, Soler P, Valeyre D: 'Sarcoidosis'. Orphanet J Rare Dis 2007;2:46. doi: 10.1186/1750-1172-2-46.

4 Henke CE, Henke G, Elveback LR, Beard CM, Ballard DJ, Kurland LT: The epidemiology of sarcoidosis in Rochester, Minnesota: a population-based study of incidence and survival. Am J Epidemiol 1986;123:840-845.

5 Chen W, Miller RA, Hebbe KA, Guron GK: Sarcoidosis and breast carcinoma: three case reports and a review. J Clin Oncol 2004;22(suppl):867.

6 Mingins C, Williams MR, Cox NH: Subcutaneous sarcoidosis mimicking breast carcinoma. Br J Dermatol 2002;146:924-925.

7 Whittington R, Lazarus A, Nerenstone S, Martin A: Sarcoidosis developing during therapy for breast cancer. Chest 1986;89:762-763.

8 Tolaney SM, Colson YL, Gill RR, Schulte S, Duggan MM, Shulman LN, Winer EP: Sarcoidosis mimicking metastatic breast cancer. Clin Breast Cancer 2007;7:804810.

9 Krawczyk BP, Gryglicka B, Kieszko R, Korobowicz E, Sojczuk S: Malignant neoplasms and pulmonary sarcoidosis - a case report. New Medicine 2004;7:9496.

-10 Gallimore AP, George CD, Lampert IA: Subcutaneous sarcoidosis mimicking carcinoma of the breast. Postgrad Med J 1990;66:677-678.

11 Gusakova I, Lavrenkov K, Ariad S, Mermershtain W: Pulmonary sarcoidosis mimicking metastases in breast cancer patients. Onkologie 2007;30:327-328.

-12 Tolaney SM, Colson YL, Gill RR, Schulte S, Duggan MM, Shulman LN, Winer EP: Sarcoidosis mimicking metastatic breast cancer. Clin Breast Cancer 2007;7:804810. 